\title{
Adding the dimension of color to computer-generated displays*
}

\author{
FREDERICK N. DYER $\dagger$ and JOHN R. SCHJELDERUP \\ U.S. Army Medical Research Laboratory \\ Fort Knox, Kentucky 40121
}

A low-cost system that permits existing computer-generated displays on a black and white CRT display to be reproduced in one of several colors on a color TV receiver is described. A black and white TV camera monitors the computer display, and the camera RF signal is sent to the color TV receiver, which has its three color guns under computer control through an interface unit described herein. In a simple on or off arrangement using three computer output relays, seven distinct and readily identifiable colors are available. With the use of $\mathrm{D} / \mathrm{A}$ converters, the interface unit is voltage controlled, permitting both faster control and many more hues to be obtained.

A computer with an associated cathode ray tube (CRT) display is a very flexible and powerful tool for conducting studies in the areas of vision, visual perception, and information processing. Very many laboratories are so equipped, but they are limited to studies involving "black and white" because of the relatively high cost of general-purpose color displays under computer control. This paper describes a low-cost system that can add the dimension of color to such displays, provided the computer is equipped with output relays (or digital-to-analog converters). Basically, it consists of a black and white TV camera that monitors the CRT display of the computer; the camera RF signal (with video modulation) is sent to a standard TV color receiver through an interface unit, described herein, which is under computer control and in turn controls the color circuits of the TV receiver. Although the versatility and speed of a standard color computer display are not obtained, many color effects that add significantly to the variables available to the researcher can be had at low cost. Specifically, the TV display is entirely in one selected color for periods of about $33 \mathrm{msec}$ and up. Rapid switching to other colors is possible with at least seven distinct and readily identifiable colors available. The system has been used extensively for presenting words in color for modified Stroop tasks. It would also be valuable for concept formation studies, color/form dominance studies, and other studies where color is a useful or essential dimension.

\section{COMPONENTS OF THE SYSTEM}

The laboratory computer used in the present system is a Digital Equipment Corporation PDP-8/I with the VC-8/I (Tektronix RM 503) oscilloscope display. The

\footnotetext{
*The technical assistance of Otto J. Dilly is gratefully acknowledged.

tRequests for reprints should be sent to Frederick N. Dyer, Experimental Psychology Division, U.S. Army Medical Research Laboratory, Fort Knox, Kentucky 40121.
}

computer is also equipped with 12 output relays and two D-A converters besides those of the oscilloscope display. A transistorized black and white television camera (Blonder-Tongue) is used to monitor the CRT with a light-tight, 4-in.-diam tube connecting camera and CRT. (A scan converter could be used to provide the video signal.) The television receiver is a 19-in. portable color set (Singer Model HE-8030), selected largely for its inexpensiveness; the unit uses vacuum tubes to control the output of its separate color guns. Like most portable sets, this receiver does not have complete transformer coupling of ac line voltages. Special care was utilized in designing an interface between the computer and TV receiver which would isolate the two units.

\section{COMPUTER/TV INTERFACE}

Electrical isolation was achieved by having the computer control the intensity of a light-emitting diode (LED) and having the voltages that bias each color gun of the receiver under control of this light. Contact closures provided through output relays or voltages from the D-A converters controlled the intensity of the LEDs. The intensity of the LED light determined the output of a light-șensitive transistor in a circuit that provided a bias voltage to an electron tube which biases the color gun of the TV receiver. The circuitry of one of three such controllers (one for each of the three guns) is schematized in Fig. 1. When the output relay contacts between $A$ and ground are open, the intensity of the LED is determined by Variable Resistor R1. For the successful on or off configuration, this resistor is adjusted to provide large conduction through Q1 and a high-intensity light output from the LED. When the D-A converter is used to control the LED intensity, a positive voltage at $\mathrm{B}$ determines the conduction of Transistor $\mathrm{Q} 1$ and hence the intensity of the LED. Transistor Q2 is photosensitive and is located as close as possible to the LED. When the LED is turned off, the circuit provides $0 \mathrm{~V}$ into the operational amplifier, $\mathrm{IC}_{1}$. Increasing LED intensity increases conduction of $\mathrm{Q}$, producing a positive voltage at the operational amplifier input. This is amplified by a factor of 8 and fed to the grid of the electron tube that biases the color gun. The effect of increasing the output of the operational amplifier is to increase the negative bias on the color gun, reducing its output. A voltage level of +3.5 turns the color off completely in this TV receiver. Grounding Point A by closing the output relay or bringing a zero voltage to Point B from the D-A converter turns the LED off and the corresponding zero output from the operational amplifier produces maximum intensity of the corresponding color gun. Capacitor $\mathrm{Cl}$ was added to the circuit to eliminate color flashes on the TV receiver that occurred during make and break of the output relay contacts. 

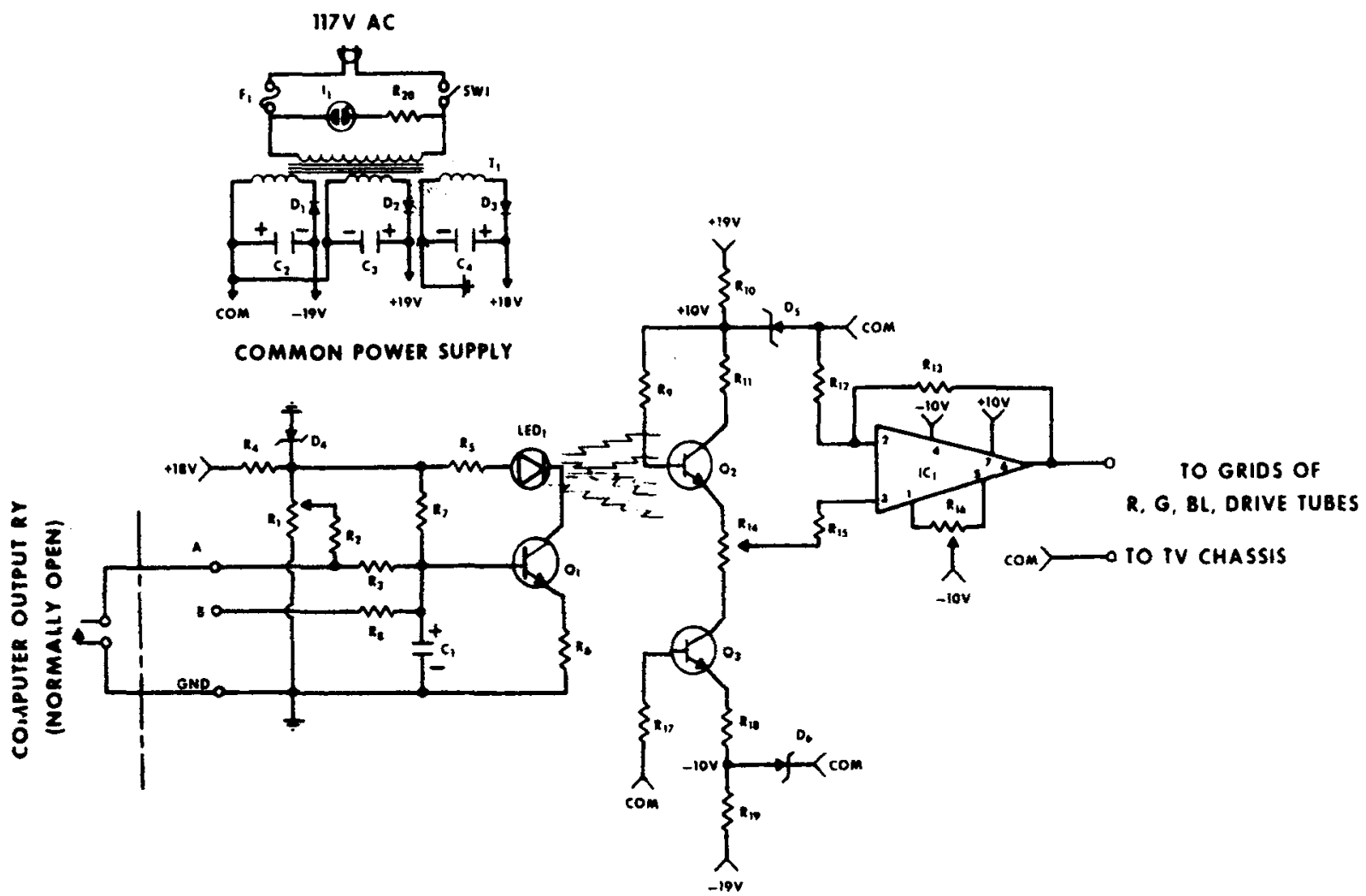

CONTROL CIRCUIT (1 of 3)

Fig. 1. Circuit diagram for common power supply and one of three controllers of TV color guns.

Table 1

Parts List for Computer/TV Interface

\begin{tabular}{|c|c|}
\hline \multicolumn{2}{|c|}{ Control Circuit (One of Three Circuits) } \\
\hline $\mathrm{C} 1$ & $2 \mu \mathrm{F} / 15 \mathrm{~V}$ \\
\hline D4 & IN756 8.2-V Zener diode \\
\hline D5, D6 & 1N758 10-V zener diode \\
\hline ICl & Operational amplifier 741 \\
\hline LED1 & Sprague ED 150 \\
\hline Q1 & $2 \mathrm{~N} 3242 \mathrm{~A}$ \\
\hline Q2 & CLT2030 (phototransistor) Clairex \\
\hline Q3 & 2 N3707 \\
\hline R1 & $10 \mathrm{~K} \Omega$ pot. \\
\hline R2, R3 & $33 \mathrm{~K} \Omega$ \\
\hline R4 & $68 \theta \Omega 1 / 2 \mathrm{w}$ \\
\hline R5, R6 & $220 \Omega$ \\
\hline R7 & $1 \mathrm{M} \Omega$ \\
\hline R8 & $22 \mathrm{~K} \Omega$ \\
\hline R9 & $\begin{array}{l}2.9 \mathrm{M} \Omega \text { to } 6.8 \mathrm{M} \Omega \text { as reqd. to produce } \mathrm{Ov} \text { at } \\
\mathrm{R} 14 \text { slider (LED off) }\end{array}$ \\
\hline R10, R19 & $470 \Omega 1 / 2 w$ \\
\hline $\mathrm{R} 11, \mathrm{R} 12, \mathrm{R} 18$ & $1 \mathrm{~K} \Omega$ \\
\hline $\mathbf{R} 13$ & $8.2 \mathrm{~K} \Omega$ \\
\hline R14 & $2 \mathrm{~K} \Omega 10$ urn pot. \\
\hline R15 & $820 \Omega$ \\
\hline R16 & $10 \mathrm{~K} \Omega$ \\
\hline R17 & $2.7 \mathrm{M} \Omega$ \\
\hline \multicolumn{2}{|c|}{ Power Supply (One Circuit) } \\
\hline $\mathrm{C} 2, \mathrm{C} 3$ & $300 \mu \mathrm{F} / 25 \mathrm{~V}$ \\
\hline & $100 \mu \mathrm{F} / 25 \mathrm{~V}$ \\
\hline D1, D2, D3 & $1 N 2482$ \\
\hline & $1 / 4 \mathrm{~A}, 250 \mathrm{~V}$ \\
\hline II & NES1 neon lamp \\
\hline $\mathbf{R} 20$ & $82 \mathrm{~K} \Omega$ \\
\hline T1 & 12a-V pri. to $3 \mathrm{sec} 12-\mathrm{V} @ .1 \mathrm{~A}$ STANCOR \\
\hline
\end{tabular}

The system has been in continuous use for several months with only one minor problem related to initial construction. Parts for the power supply and one TV color-gun controller are listed in Table 1.

\section{PROGRAMMING SINGLE AND MULTIPLE COLOR DISPLAYS}

Since energizing the output relay corresponding to a color gun increases the intensity of that color, energizing all three relays produces a white color that is the sum of the red, blue, and green outputs. Red, blue, and green are each produced by energizing the single relay corresponding to the relevant color gun. Energizing the red and green relays together produces yellow. Energizing the red and blue relays simultaneously produces purple, and energizing the blue and green relays together produces a desaturated blue. Except for the desaturated blue, all hues are excellent representations of their class and show no large differences in apparent brightness. They are identical in appearance to the highly saturated colors that appear in test patterns or in TV reception exemplified by the Saturday morning color cartoons. Contrast and brightness controls of the receiver are adjusted so that the colored figures or alphanumerics appear on a black background.

No flicker or roll of the TV display is noticeable, because the CRT display is refreshed 100 times/sec. Displays that require longer painting time $(40 \mathrm{msec}$ oi 
more) might be shown on a CRT having a much longer phosphor persistence.

Exploitation of this successful all-or-none configuration has delayed exploration of graded control of color guns by use of computer D-A converter voltages. However, to obtain some idea of the possibilities that such operation would provide, two of the color guns were interfaced to the two available D-A converters. Capacitor $\mathrm{Cl}$ was removed from each controller to allow for rapid changes of color during the scan of a single raster. D-A voltage conversions were adjusted to a rate that was some integral multiple of the color TV frame rate. This permitted different portions (top to bottom) of the TV display to be in different colors. By using different voltages, a wide range of hues was obrainable. The interface unit is the slowest part of this system; yet it is fast enough so that approximately succeeding lines of the TV raster can be made different in color or intensity. This points to the possibility (with proper synchronization) for generating sinusoidal or other spatial gratings made up of one or more colors that might be useful as stimuli in studies of basic color vision processes.

(Received for publication June 15, 1973: revision received September 18.1973.) 